Research Article

\title{
Green Synthesis of Gold Nanoparticles by Using Peltophorum Pterocarpum Flower Extracts
}

\author{
Madheswaran Balamurugan $^{1 \llbracket}$, Saravanan Kaushik², Shanmugam Saravanan ${ }^{1}$ \\ ${ }^{1}$ Centre for Photonics and Nanotechnology, Department of Science, Sona College of Technology, Salem - 636005, Tamil Nadu, India. \\ ${ }^{2}$ The Indian Public School, Senapathipalayam, Erode - 638112, Tamilnadu, India.
}

Corresponding author. E-mail: chem.muruga@gmail.com; Tel: +91 0427 4099892; Fax: +91 04274099888

Received: Aug. 2, 2016; Accepted: Oct. 24, 2016; Published: Nov. 4, 2016.

Citation: Madheswaran Balamurugan, Saravanan Kaushik and Shanmugam Saravanan, Green Synthesis of Gold Nanoparticles by Using Peltophorum Pterocarpum Flower Extracts. Nano Biomed. Eng., 2016, 8(4): 213-218.

DOI: 10.5101/nbe.v8i4.p213-218.

\begin{abstract}
A facile, green method was developed for the synthesis of stable gold nanoparticles using Peltophorum pterocarpum flower extracts as both reducing and capping agents. The influence of temperature on experiment was studied. The obtained gold nanoparticles were characterized by ultra violet-visible spectroscopy and high resolution transmission electron microscopy. The ultra violetvisible spectroscopy shows the absorbance band around $560 \mathrm{~nm}$, and the high resolution transmission electron microscopy illustrates that the nanoparticles are spherical in shape with size ranging from $5-50 \mathrm{~nm}$.
\end{abstract}

Keywords: Gold nanoparticles; Green synthesis; Colloidal synthesis; Biological synthesis; Metal nanoparticles

\section{Introduction}

Nanotechnology emerges from the physical, chemical, biological and engineering sciences where novel techniques are being developed to probe and manipulate single atoms and molecules. Also, nanotechnologies can be defined as the production, characterization, design, and application of structures, devices and systems by controlling shape and size at a nanometer scale. The creation of nanoscale materials with highly developed structures has led to a growing interest in the area of bio-mineralization. Numerous biomaterials are capable of synthesizing nano structures. In medicine, most interest is in the use of nanoparticles to enhance drug delivery, with interest also in in vitro diagnostics, novel biomaterial design, bio-imaging, therapies and active implants [1]. Noble metal nanoparticles such as gold, silver, and platinum are widely used in products that directly contact with the human body, such as shampoos, soaps, detergent, shoes, cosmetic products, and toothpaste, in addition to medical and pharmaceutical applications [2]. Among the noble metal nanoparticles, gold has enormous potential applications in various fields [3]. Gold nanoparticles (Au NPs) are used in a wide range of applications including opto-electronic devices [4, 5], catalysis [6], biomedical including DNA labeling and drug delivery [7-9], cell imaging [10], immune staining [11], biosensors [12] and cancer therapy [13, 14] due to its exceptional properties. Synthesis of nanomaterial with superior properties is one of the important phases in nanoscience for different types of applications. 
Different synthetic techniques for synthesis of metal nanoparticles exist, such as bottom-up and top-down approaches. To date, a wide range of choices of physical and chemical processes for metallic nanoparticle synthesis have been reported. However, physical methods include evaporation and laser ablation, whereas chemical methods involve the reduction of a salt with reducing agents. The development of new chemical or physical methods has resulted in environmental contaminations, since the chemical processes involved in the synthesis of nanomaterials generate a large amount of hazardous byproducts [15]. The growing demand for environmentally benign synthesis techniques has led to the use of biological entities for nanoparticle synthesis [16]. Currently, we are in the vital need of developing safe, reliable, clean and eco-friendly methods for the preparation of nanoparticles. Comparatively, the biosynthesis of metal nanoparticles, as an emerging highlight of the intersection of nanotechnology has received increasing attention due to a growing need to develop rapid, clean, non-toxic, simple and environmentally friendly synthetic technologies with cost effectiveness. Biosynthetic methods can engage either microorganism cells or plant extract for nanoparticles production [17].

The use of plants parts instead of traditional toxic chemicals in similar synthesis methodologies is a stimulating prospect that is currently under enormous investigation, having significant potential utilization [18]. Among these biological ingredients, plants are considered as the best candidates and they are suitable for large-scale biosynthesis of nanoparticles [19]. This method is a reproducible alternative to the chemical synthesis. The utilization of cheap nontoxic chemicals, eco-friendly solvents and renewable materials is of crucial importance in the green synthesis strategy of nanomaterials. Using plants for nanoparticle synthesis can be advantageous over other biological processes, because it eliminates the elaborate process of maintaining cell cultures and can also be suitably scaled up for large-scale nanoparticle synthesis. Quite a few studies have been successfully reported in the synthesis of silver and gold nanoparticles by using plant parts. Even with the many previous reports, it is still necessary to identify new tropical plants for the synthesis of nanoparticles. Since some of the plants are not easily obtained and are only accessible in limited areas. Hence collecting those particular plants can be expensive. It leads to finding new tropical plants which have the reducing and capping properties. In this present study, the gold nanoparticles have been prepared using Peltophorum pterocarpum (PP) flower extracts as both reducing and capping agents. PP (Fig. 1) is a native tropical plant belonging to the Fabaceae family. PP flowers contain carbohydrates, reducing sugars, sterols, tannin, glycosides and flavonoids [18]. Recently the silver nanoparticle has been successfully synthesized using PP flower extract as reducing and capping agents [20, 21].

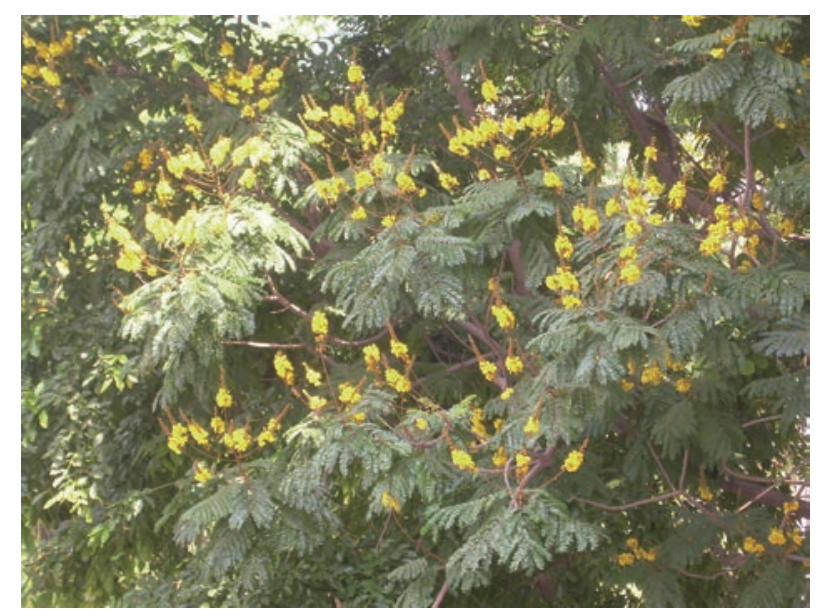

Fig. 1 Photograph of Peltophorum pterocarpum flower.

\section{Experimental}

\section{Materials}

Gold (III) chloride hydrate $\left(\mathrm{HAuCl}_{4} \cdot \mathrm{xH}_{2} \mathrm{O}\right)$ was purchased from Sigma-Aldrich and used as received. PP flowers were harvested from our campus. Double distilled de-ionized (DI) water was used throughout the experiment.

\section{Synthesis of gold nanoparticles}

The flower extract was prepared by boiling $1 \mathrm{~g}$ of PP flowers in $100 \mathrm{~mL}$ of DI water at $80{ }^{\circ} \mathrm{C}$ for $30 \mathrm{mins}$. Finally, it was filtered to separate out the broth and stored at $5{ }^{\circ} \mathrm{C} .20 \mathrm{~mL}$ of obtained PP flower extract was slowly dripped into $1 \mathrm{mM}$ aqueous Gold (III) chloride hydrate with constant stirring at room temperature as well as at elevated temperatures $\left(50,60\right.$ and $\left.70{ }^{\circ} \mathrm{C}\right)$. After the completion of flower extract and gold precursor mixing, the experimental temperature was maintained for another 30 mins. The formation of Au NPs was confirmed as observed by the colour change of this colloidal solution from yellow to pink.

\section{Results and Discussions}

The PP flower extract was employed as a reducing 

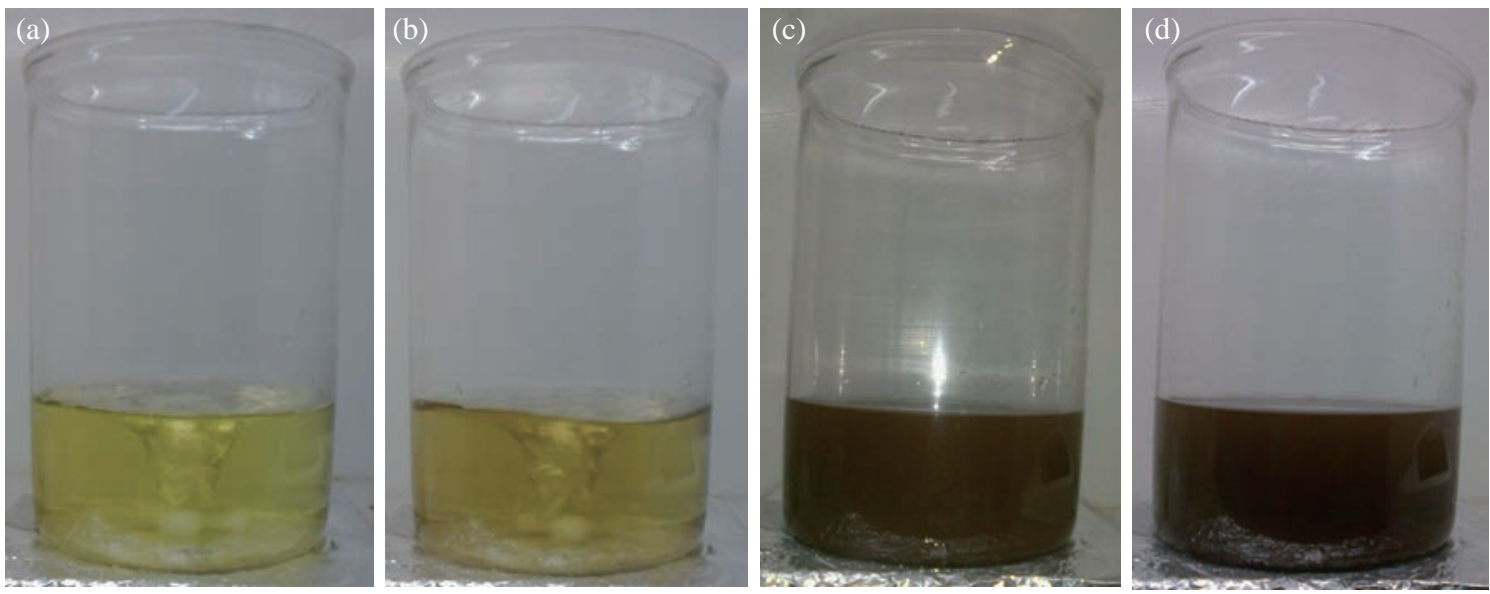

Fig. 2 Photographs of aq. $\mathrm{HAuCl}_{4} \cdot \mathrm{xH}_{2} \mathrm{O}$ (a) before adding the $20 \mathrm{~mL}$ of flower extract, and (b)-(d) after adding the flower extract for different timings.

and capping agent in synthesis of Au NPs. The gold nanoparticles were synthesized at ambient temperature as well as at elevated temperature. When the PP flower extract was mixed with the aqueous solution of gold ion, the solution started to change colour from yellow to pink due to the reduction of gold ions [14].

Fig. 2 shows the digital photographs of aq. $\mathrm{HAuCl}_{4}$. $\mathrm{xH}_{2} \mathrm{O}$ before adding the flower extract and after adding the $20 \mathrm{~mL}$ of flower extract for different timings. The color appearance in the mixed solution was a primary identification of metal nanoparticles' formation. The attribution of colour depended on the nano dimensions of gold. That the pink colour arose in colloidal Au NPs was due to the excitation of surface plasmon vibrations in the metal nanoparticles [14, 22]. The surface plasmon resonance and formation of Au NPs was examined by the UV-Vis (ultra violet-visible spectroscopy) absorbance spectrum. UV-Vis absorption spectrum was performed using UV-Vis double-beam bio-spectrophotometer ELICO-BL-198 with the software version 2.37.4 REL-1. After the addition of PP plant extract into the aqueous solution of gold ion, the solution was filled in glass cuvette of path length $10 \mathrm{~mm}$, and UV-Vis spectral analysis was done in the range of 400 to $800 \mathrm{~nm}$ with the periodic time intervals of 5, 30, 60, 90, 120 and 1,200 mins. Double distilled de-ionized water was used as the reference.

Fig. 3 shows the UV-Vis spectra of Au NPs and illustrates the reduction of gold ions and the formation of nanoparticles. After adding the PP flower extract into the gold precursor, the intensity of UV-Vis absorbance band increased with time duration, which indicated the formation of Au NPs. The spectra show the characteristic surface plasmon band around 530 to $550 \mathrm{~nm}$ and confirm the presence of Au NPs. The UV-Vis spectra of obtained Au NPs were acquired to investigate the optical properties. The surface plasmon band arose due to the excitation of electrons in the conduction band of Au NPs induced by the electromagnetic field [14]. After the mixing of flower extract and the gold precursor, the UV absorbance increased in fast manner up to 90 mins as shown in the Fig. 3. And then the intensity difference was relatively smaller when the time increased. Fig. 4 shows the increase in UV absorbance intensity as the time increased. This indicates the rate of formation of nanoparticles was high in the initial stage, and that as the time increased it gradually reduced.

The experimental temperatures had an influence on the formation of nanoparticles. The higher temperature supported the formation of small-size particles [20]. Comparably, the intensity of UV-Vis spectrum increased faster in higher experimental temperatures than in room temperature. It was exhibited that the rate of the reaction/formation of Au NPs was higher in elevated temperatures than in room temperature. The rate of reaction was faster than the time required for gold nanoparticle synthesis using the same flower extract at room temperature. The UV-Vis absorption band appeared around 557, 542, 532 and $532 \mathrm{~nm}$ for $\mathrm{Au}$ NPs prepared at room temperature, 50, 60 and 70 ${ }^{\circ} \mathrm{C}$ respectively. It illustrates when the experimental temperature was increased the UV-Vis absorbance band got blue shift. The blue shifting corresponded to the size reduction of particles. Moreover, the full width at half maximum (FWHM) of UV-Vis band also decreased as shown in Fig. 5. The decreases in FWHM of absorbance band depended on the size 

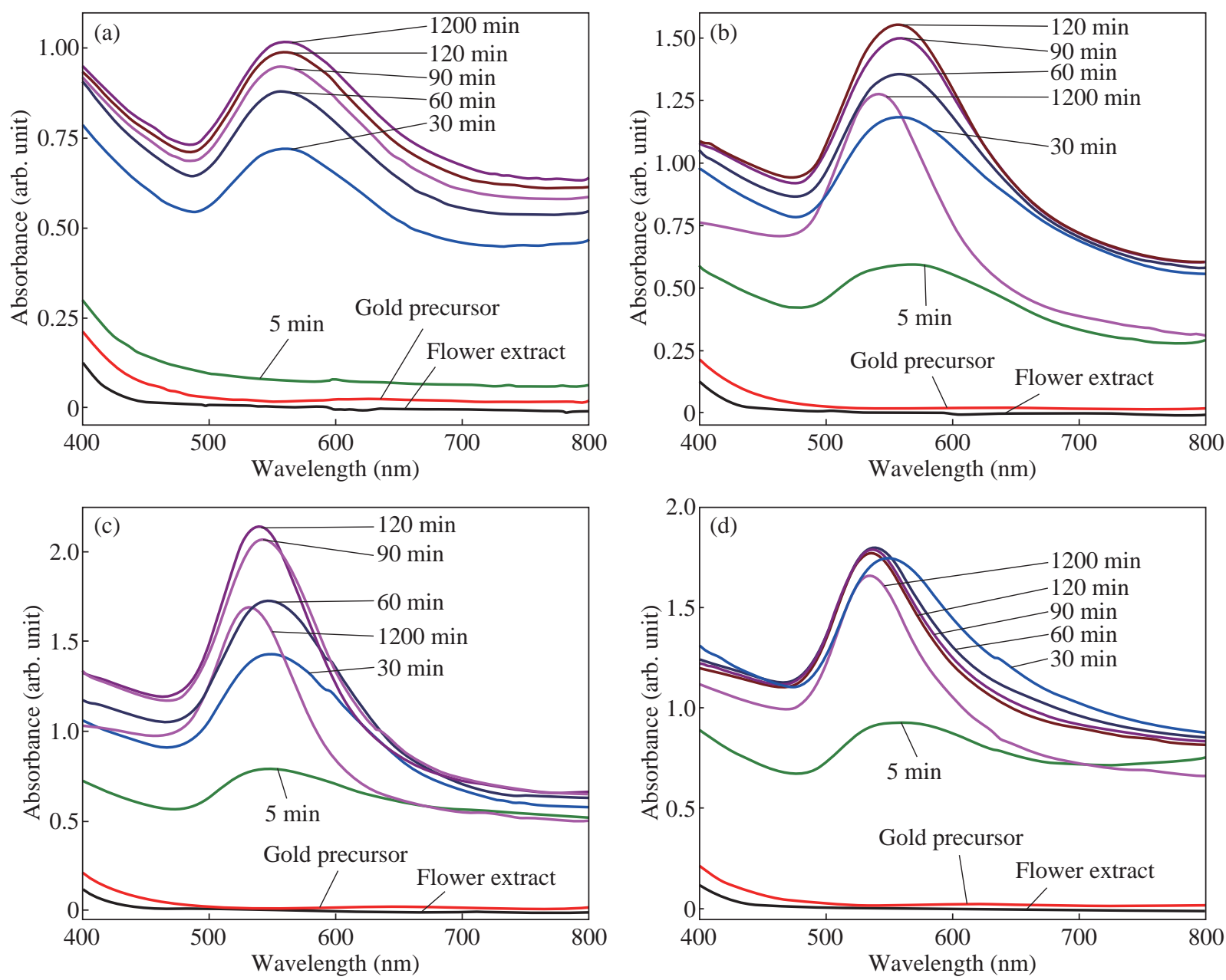

Fig. 3 UV-vis spectra of gold nanoparticles prepared form $1 \mathrm{mM}$ Gold (III) chloride and $20 \mathrm{~mL}$ flower extract at (a) ambient temperature, (b) $50^{\circ} \mathrm{C}$, (c) $60{ }^{\circ} \mathrm{C}$ and (d) $70{ }^{\circ} \mathrm{C}$ for different time intervals.

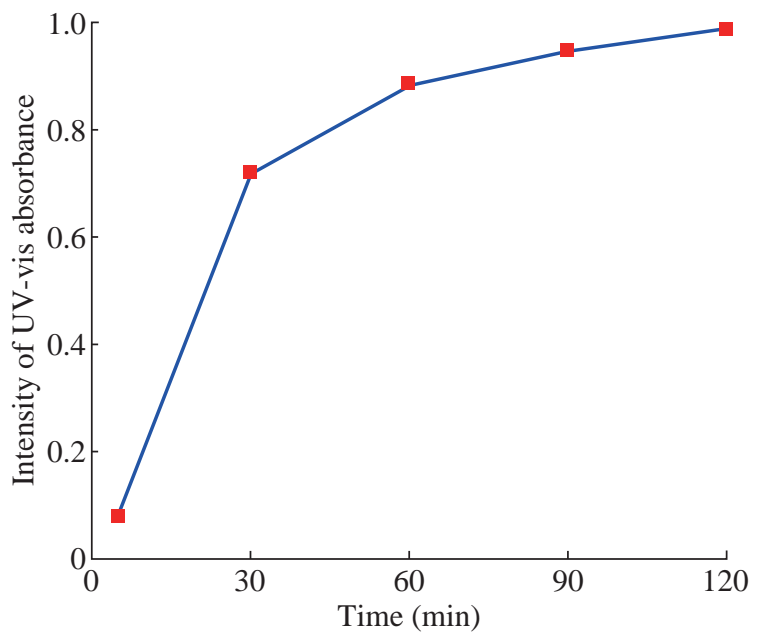

Fig. 4 The intensity of UV-Vis absorbance of gold nanoparticles with time at room temperature.

and uniformity of the synthesized nanoparticles. In higher temperatures the particles may be smaller with better uniformity. Further when we increased the experimental temperature from $60{ }^{\circ} \mathrm{C}$ to $70{ }^{\circ} \mathrm{C}$, there

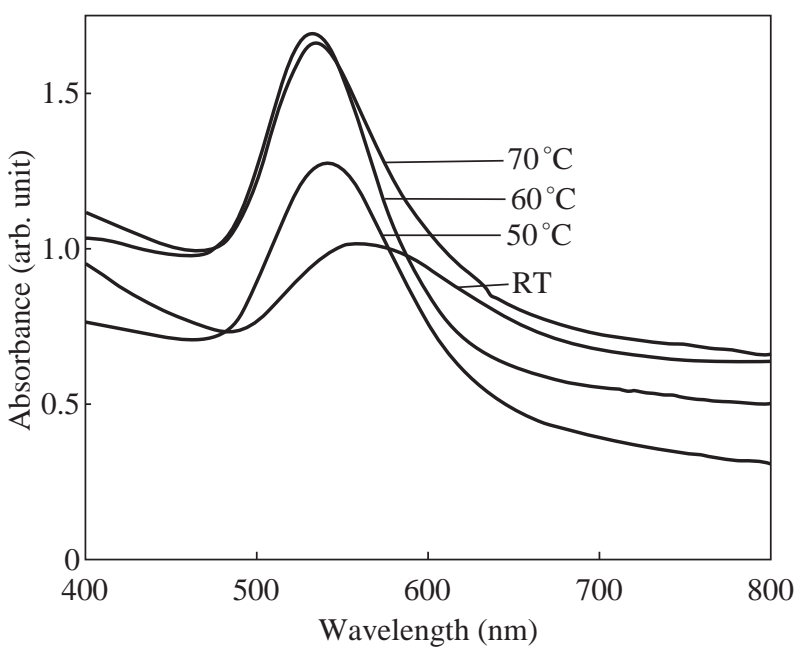

Fig. 5 UV-vis spectra of gold nanoparticles prepared from $1 \mathrm{mM}$ Gold (III) chloride and $20 \mathrm{~mL}$ flower extract at (a) ambient temperature, (b) $50{ }^{\circ} \mathrm{C}$, (c) $60^{\circ} \mathrm{C}$ and (d) $70{ }^{\circ} \mathrm{C}$ after 1,200 mins.

was no blue shift in UV-Vis band. Also, the intensity of UV-Vis spectra was comparably higher at $60^{\circ} \mathrm{C}$ than at other temperatures. 

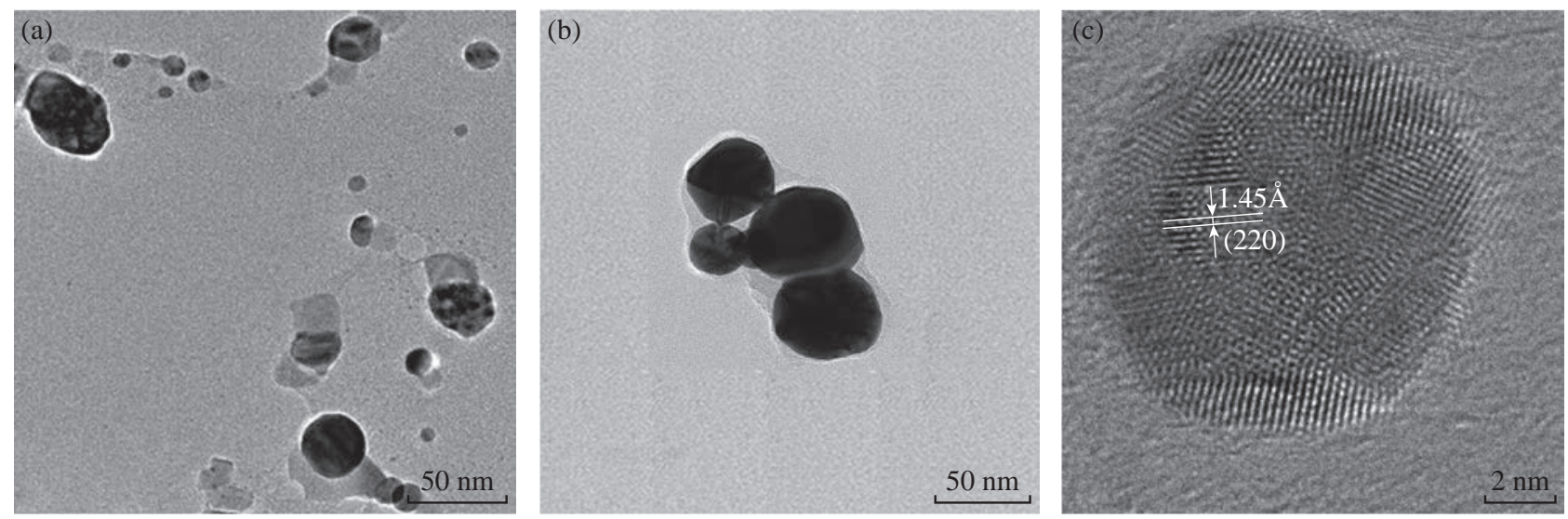

Fig. 6 TEM images of gold nanoparticles prepared form $1 \mathrm{mM}$ Gold (III) chloride and $20 \mathrm{~mL}$ flower extract at (a) ambient temperature, and (b) $60^{\circ} \mathrm{C}$. (c) HR-TEM image of gold nanoparticles prepared at ambient temperature.

The obtained silver particles were analyzed by HR-TEM (high resolution transmission electron microscopy) for morphological analysis as well as for size determination. TEM (transmission electron microscopy) analysis was done by using a JEOLJEM-2100F (FE-TEM). The specimen for HR-TEM was prepared by casting a drop of prepared solution on a standard carbon coated copper grid; the excess solution was removed by blotting paper and allowed to dry under ambient conditions. Fig. 6 shows the TEM images of Au NPs. The images showed the presence of spherical nanostructure Au NPs with good dispersion. The capping of Au NPs by bio-component from the flower extract was visible from the TEM pictures. Fig. 6(a) and (b) show the TEM images of Au NPs prepared at ambient temperature and at $60{ }^{\circ} \mathrm{C}$ respectively. As shown in Fig. 6(a), the particles were well dispersed and the size varied from 5 to $55 \mathrm{~nm}$. Fig. 6 (b) shows the Au NPs prepared at $60{ }^{\circ} \mathrm{C}$. The particles sizes were relatively uniform of around 30 to $50 \mathrm{~nm}$. It exhibits that the higher temperature $\left(60{ }^{\circ} \mathrm{C}\right)$ supported the formation of more uniform particles. This result was in good agreement with UV-Vis spectroscopy of Au NPs prepared at $60{ }^{\circ} \mathrm{C}$.

Fig. 6(c) shows the HR-TEM image of the gold nanoparticles prepared at ambient temperature. The distributions of lattice springs were presented well with the well defined grain boundaries. Hence, HR-TEM exhibited that the prepared Au NPs were polycrystalline in nature. The lines drawn on the HRTEM image (Fig. 6(c)) showed that the fringe spacing of Au NPs was $1.45 \AA$ which corresponded well to the spacing between (220) plane of face centered cubic (FCC) gold [23].

\section{Conclusions}

The synthesis of gold nanoparticles by reducing $\mathrm{HAuCl}_{4} \cdot \mathrm{xH}_{2} \mathrm{O}$ with the Peltophorum pterocarpum flower extract was investigated. The bio-molecules which are present in Peltophorum pterocarpum flower extract played a dual role as reducing and capping agents. The sizes of the prepared gold nanoparticles varied from 10 to $30 \mathrm{~nm}$ with a spherical shape. The gold nanoparticles were prepared at ambient as well as at elevated temperatures. The bio-reduction of gold ions by flower extract could be promoted at higher temperatures, especially at $60{ }^{\circ} \mathrm{C}$. Increasing the experimental temperature supported the formation of small-size particles. The obtained gold nanoparticles were remarkably stable and remained unchanged after several days of storage under ambient conditions. The gold nanoparticles prepared in the above size range can be applied in areas of nonlinear optics and solar cells, where very small gold nanoparticles are required.

\section{References}

[1] S. Jain, D.G. Hirst and J.M. O’Sullivan, Gold nanoparticles as novel agent for cancer therapy. The British Journal of Radiology, 2012, 85: 101-113.

[2] J.Y. Song, H.K. Jang and B.S. Kim, Biological synthesis of gold nanoparticles using Magnolia kobus and Diopyros kaki leaf extracts. Process Biochemistry, 2009; 44: 11331138.

[3] M.C. Daniel, D. Astruc, Gold nanoparticles: Assembly, supramolecular chemistry, quantum-size related properties and applications towards biology, catalysis and nanotechnology. Chem. Rev., 2004, 104: 293-340.

[4] D.H. Gracias, J. Tien, T.L. Breen, et al., Forming electrical networks in three dimensions by self assembly. Science, 2000, 289: 1170-1172.

[5] J.H. Park, Y.T. Lim, O.O. Park, et al., Enhancement of photostability in blue-light emiting polymers doped with 
gold nanoparticles. Macromol. Rapid Commun, 2003, 24 : 331-334.

[6] M.M. Maye, Y. Lou and C.J. Zhong, Core-shell gold nanoparticles assembly as novel electrocatalyst of CO oxidation. Langmuir, 2000, 16: 7520-7523.

[7] J.C. Sanford, F.D. Smith and J.A. Russell, Optimizing the biolistic process for different biological applications. Method. Enzymol., 1993, 217: 483-509.

[8] R. Elghanian, J.J. Storhoff, Selective colorimetric detection of polynucleotides based on the distancedependent optical properties of gold nanoparticles. Science, 1997, 277: 1078-1081.

[9] J.J. Storhoff, R. Elghanian, C.A. Mirkin, et al., Sequencedependent stability of DNA-modified gold nanoparticles. Langmuir, 2002, 18: 6666-6670.

[10] A. Bielinska, J.D. Eichman, Imaging \{Au0-PAMAM \} gold-dendrimer nanocomposites in cells. J. Nanopart. Res., 2002, 4: 395-403.

[11] E.A.E.A. El-Drieny, N.I. Sarhan, N.A. Bayomy, et al., Histological and immunohistochemical study of the effect of gold nanoparticles on the brain of adult male albino rat. Journal of Microscopy and Ultrastructure, 2015, 3: 181190.

[12] J. Roth, The silver anniversary of gold: 25 years of the colloidal gold marker system for immunocytochemistry and histochemistry. Histochem. Cell. Biol., 1996, 106: 1-8.

[13] N.S. Abadeer, C.J. Murphy, Recent progress in cancer thermal therapy using gold nanoparticles. J. Phys. Chem. C, 2016, 120: 4691-4716.

[14] M.M.R. Mollick, B. Bhowmick, D. Mondal, et al., Anticancer (in vitro) and antimicrobial effect of gold nanoparticles synthesized using Abelmoschus esculentus (L.) pulp extract via a green route. RSC Adv., 2014, 4: 37838-37848.

[15] E. Amato, Y.A. Diaz-Fernandez, A. Taglietti, et al., Synthesis, characterization and antibacterial activity against gram positive and gram negative bacteria of biomimetically coated silver nanoparticles. Langmuir, 2011, 27: 9165-9173.

[16] R. Bali, A.T. Harris, Biogenic synthesis of Au nanoparticles using vascular plants. Ind. Eng. Chem. Res., 2010, 49: 12762-12772.

[17] S.S. Shankar, A. Rai, A. Ahmad, et al., Rapid synthesis of Au, Ag, and bimetallic Au core Ag shell nanoparticles using Neem (Azadirachta indica) leaf broth. J Colloid Interface Sci., 2004, 275: 496-502.

[18] B. Raju, C. Vijaya and A. Ramu, Evaluation of cardiotonic activity of Peltophorum pterocarpum, Inter J Phytopharmacol., 2011, 2: 1-6.

[19] S. Iravani, Green synthesis of metal nanoparticles using plants, Green Chem., 2011, 13: 2638-2650.

[20] M. Balamurugan, N. Kandasamy, S. Saravanan, et al., Synthesis of uniform and high-density silver nanoparticles by using Peltophorum pterocarpum plant extract, Jpn. J. Appl. Phys., 2014, 53: 05FB19(1-7).

[21] M. Balamurugan, S. Saravanan and N. Ohtani, Synthesis of uniform and high density silver nanoparticles by using Peltophorum pterocarpum flower extract. MRS Proceedings, 2014, 1584: jsapmrs13-1584-7162.

[22] P. Mulvaney, Surface plasmon spectroscopy of nanosized metal particles. Langmuir, 1996, 12: 788-800.

[23] N. Mejías, A. Serra-Muns, R. Pleixats, et al., Watersoluble metal nanoparticles with PEG-tagged 15-membered azamacrocycles as stabilizers. Dalton Trans., 2009, 37: 7748-7755.

Copyright $@ 2016$ Madheswaran Balamurugan, Saravanan Kaushik and Shanmugam Saravanan. This is an open-access article distributed under the terms of the Creative Commons Attribution License, which permits unrestricted use, distribution, and reproduction in any medium, provided the original author and source are credited. 